\title{
In vitro Biosynthesis of Human Placental Lactogen (HPL) by Chorionic Tissue and the Diagnostic Value of HPL in Trophoblastic Disease
}

\author{
YOSHIAKI SATO \\ Department of Obstetrics and Gynecology, Niigata University School \\ of Medicine, Niigata
}

\begin{abstract}
Synopsis
With an aim to elucidate the significance of Human Placental Lactogen (HPL) during gestation, I assayed the HPL and HCG concentration in the chorionic tissue and the blood. The results as follows:

1) There was a definite correlation between the HPL concentration in the maternal serum at term and the weight of the neonates, which might lead to an idea that HPL took part in the growth of fetuses as a metabolic hormone during pregnancy.

2) It was suggested by short term incubation and the cell culture experiment that HPL concentration in the molar tissue was almost the same as or slightly higher than that of the normal chorionic villi, while the serum HPL concentration of molar patient was significantly lower than that of normal pregnant woman.

3) A simultaneous determination of HPL and HCG in serum of trophoblastic disease showed that the HPL/HCG ratio could be useful for differential diagnosis of trophoblastic disease.
\end{abstract}

Ito \& Higashi (1961) suggested an existence of lactogenic substance in the placenta. Josimovich \& MacLaren (1962) found a protein with the lactogenic action in the maternal serum at term, placental blood and placental tissue, and called it HPL. It has been known that HPL has an immunologically partial identity with the Human Growth Hormone (HGH).

Midgley \& Pierce (1962) showed that HCG was secreted from syncytiotrophoblast. Sciarra et al. (1963) and Currie et al. (1966) proved that HPL was localized in the same syncytiotrophoblast using the immunofluorescent antibody method. It has been known that this hormone has probably the sommatotropic and metabolic actions, that is, a combinational action of Prolactin and HGH.

However, the role of HPL in gestation has still largely unknown. In this study, I assayed

Received for publication May 10, 1973. the HPL concentration in the tissue extract and serum using the HAIR and RIA. Further, a simultaneous assay of HCG and HPL of the serum was performed. It was discussed whether or not it could be useful for differential diagnosis of trophoblastic disease.

\section{Materials and Methods}

The fresh chorionic villi or placental tissue and chorionic villi of hydatidiform mole were used as the material for bioassay on Prolactin, homogenization and incubation experiment for HPL.

That is, they were obtained aseptically on artificial abortion or on D. \& C. of hydatidiform mole or immediately after delivery and put to experiment as soon as possible.

As for the samples for measuring blood hormone, fasting blood was drawn at 9.00 a.m. from a total of 97 cases in various stage of normal pregnancy, while the blood was drawn from 20 cases of hydatidiform mole, 3 cases of destructive mole and 3 cases of chorionepithelioma for a total of 26 cases of 
trophoblastic disease: then, serum was isolated immediately and kept at $-20^{\circ} \mathrm{C}$ until time of assay.

Further, the blood was collected before the onset of labor from 36 normal pregnant women at term of pregnancy; and, the weight of placenta and the weight of neonates were measured and recorded on the same person after delivery.

As to the placenta, a part of which was collected at delivery and subjected to the incubation experiment.

\section{A) Incubation experiment}

The normal chorionic villi or placental tissue and chorionic villi of hydatidiform mole were put to the incubation experiment.

The incubation was effected in accordance with Takahashi's (1970) short-term incubation system for the anterior lobe of pituitary.

That is, a fresh placental tissue or chorionic villi was collected and $1 \mathrm{~g}$ of which was weighed accurately after rinsing twice with Dulbecco's (1954) phosphate buffer (A-solution), washing away the blood and removing the water content lightly with a filter.

It was cut to peices fully for a certain time with ophthalmologist's scissors; then, the peices were placed in a $50 \mathrm{~m} l$ glass flask; with $5 \mathrm{~m} l$ of a $0.2 \%$ glucose-added Krebs-Ringer phosphate buffer $\mathrm{pH}$ 7.4 (Medium) added thereto, the flask was sealed with paraffin and subjected to the shaking culture at $80 \mathrm{cycle} / \mathrm{min}$ for $2 \mathrm{hr}$ in an incubator.

Refrigerated centrifugation was performed thereon at $3,000 \mathrm{rpm}, 4^{\circ} \mathrm{C}$ for $10 \mathrm{~min}$ immediately after termination of incubation; the supernatant thus obtained was made a sample.

Regarding the chorionic villi of hydatidiform mole, it was subjected to the same procedure except that the whole tissue was incubated without being cut to pieces.

\section{B) Homogenization}

For comparative purposes with the incubation medium, $1 \mathrm{~g}$ of the above-mentioned tissues was weighed accurately, and homogenized with $5 \mathrm{ml}$ of Krebs-Ringer phosphate buffer. It was centrifuged at 3,000 rpm for $5 \mathrm{~min}$; and, the supernatant thus obtained was made a sample.

\section{C) Monolayer cell culture}

The chorionic tissue collected aseptically was preserved in the Hanks-solution and washed three times with a trypsin solution, to which was added a $0.25 \%$ trypsin and the chorionic villi was cut to pieces $1-2 \mathrm{~mm}$.

The peices were shaken in a $0.25 \%$ trypsin solution for 2 minutes, and the supernatant thus obtained was centrifuged at 1,000 rpm for $7 \mathrm{~min}$, and then it was diluted with the growth medium (Eagel MEM $+20 \%$ calf serum) so that the number of cells amount to $20-30 \times 10^{3} / \mathrm{ml}$.

The dilution was divided into a microtube for examination of chromosome and a plaque bottle for incubation, and then incubation was effected in an incubator at $37^{\circ} \mathrm{C}$.

The growth medium was exchanged every 3 days in principle; however, it was exchanged one day earlier or later depending on the conditions of cells.

The medium was replaced entirely and after the cells had been washed with the Hanks-solution 2-3 times, a new medium was put in.

\section{D) Determination of hormone \\ (1) Determination of prolactin}

Nicoll's (1967) pigeon crop sac assay, a bioassay was employed.

That is, Japanese house-pigeons weighing $300 \mathrm{~g}$ 2-3 months after incubation were reared under same environments for about one week after receipt and then put to experiments.

Physiological saline solution $0.1 \mathrm{~m} l$ as the control was injected to the epithelium immediately above the crop sac on the right and an unknown sample in the same dose on the left, each twice a day (9:00 a.m. and 5:00 p.m.) for 2 days; the bird was sacrificed by decapitation on the 3rd day; the crop sac was removed in such a manner as not spoiling it; with the mumbranous epithelium of its reacted part scraped off, it was let alone in a $110^{\circ} \mathrm{C}$ desiccator for $24 \mathrm{hr}$, and then its dry weight was weighed.

As assay for prolactin, an increase in the dry weight of the membrane with the control deducted was made the value of it, comparing with the standard prolactin value.

\section{(2) Determination of $H P L$}

Lederle Lab. lot No. 4508 C75 (purity 95-98\% A. Glick M. D.) was used as the standard HPL, and in determining it, HAIR and RIA, immunological assay were employed suitably.

HAIR was employed in accordance with the method of Odajima (1972) of this department. That is: (a) Preparation of $B D B$ (benzidine dihydrochloride)

BDB $640 \mathrm{mg}$ was dissolved in distilled water $103 \mathrm{ml}$ and the solution was adjusted to $\mathrm{pH} 9.0$; a container containing this solution was placed in ice, into which was poured a $10 \% \mathrm{NaNO}_{2} 3.4 \mathrm{~m} l$ slowly; when this solution turned yellow, $1 \mathrm{ml}$ each was poured into a tube and stored at $-20^{\circ}$.

(b) Anti-serum

HPL $3 \mathrm{mg}$ in a state of equivalent Freund complete adjuvand and oily drop in water was injected subcutaneously to the back of a New Zealand white rabbit; after giving a total of 3 injections at an interval 
of 2-3 weeks, its antibody value was examined by HAIR; and it was made inactive for storage after total bleeding and separation of serum, if enough antibody was obtained. (antibody value 1:10,00013,000.).

\section{(c) Preparation of sensitized $R B C$}

$9 \mathrm{ml}$ of a $10 \%$ formalin $\mathrm{RBC}$, after washing, was dissolved in pH 7.4 phosphate buffer $30 \mathrm{~m} l$, to which was added HPL $2 \mathrm{mg}$, and the mixture was shaken; BDB $1 \mathrm{~m} l$ and phosphate buffer $14 \mathrm{~m} l$ were added thereto; $10 \mathrm{~m} l$ of the mixture was taken and poured into a flask containing HPL and RBC; then, the solution was made to act for $13 \mathrm{~min}$; after washing with phosphate buffer three times, it was adjusted in a $0.02 \%$ BSA solution so that it becomes a $1.5 \%$ $\mathrm{RBC}$ solution, and the solution thus adjusted was stored at $-4^{\circ} \mathrm{C}$.

Using these solutions, the measurement was undertaken.

Instruments used were an automatic diluting syringe and disposable tray of Cornwall (Model RB $98-16 \times 8$ holes).

As for the evaluation, the HPL concentration was assessed by comparing standards $1 \mu \mathrm{g}$ and $0.5 \mu \mathrm{g}$ with the sample. The lower limit of sensitivity was $0.5 \mu \mathrm{g} / \mathrm{ml}$.

The HPL RIA used in this study was a double antibody method.

(1) Radioiodination was carried out with ${ }^{125} \mathrm{I}$ using the chloramin $\mathrm{T}$ method of Greenwood \& Hunter (1963) and purified by gel filtration on Sephadex G75.

${ }^{125} \mathrm{I}$ HPL was diluted to give $15 \times 10^{3}$ counts per minute per $0.1 \mathrm{~m} l$ (HPL concentration $0.1-0.2$ $\mathrm{ng} / \mathrm{m} l)$.

(2) Antibodies to HPL were raised in New Zealand white rabbit as mentioned above. Since the potency of the antiserum may vary greatly, it may be necessary to include the point of its equivalence with antigen, so that it was used in a final dilution of $1: 100,000$ antiserum giving $40-60 \%$ binding of the labelled hormone.

The antigen used for antibody production and the preparation reference standards were the same HPL as that used in HAIR. RIA was set up as follows: (a) $0.3 \mathrm{ml}$ each of phosphate buffer containing a $0.5 \% \mathrm{BSA}$ of $\mathrm{pH} 7.4$ was put in a tube using the micro pipet of Oxford, to which was added the sample (dil: $1: 1$ to $1: 100$ ) or standard $0.1 \mathrm{ml}$ each.

(b) Anti-serum $0.1 \mathrm{~m} l$ was put in each tube.

(c) $0.1 \mathrm{~m} l$ of ${ }^{125} \mathrm{I}$ HPL was added in each tube.

(d) This tube was admixed well with a mixer, and then it was placed in a refrigerator and incubated for 24-30 hr.

(e) After incubation, the solution was mixed well and then $0.1 \mathrm{~m} l$ of anti-rabbit goat gammagolblin serum (Dainabot Co.) was injected for the purpose of separating the Bound from the Free, and further incubation was effected at $4{ }^{\circ} \mathrm{C}-2{ }^{\circ} \mathrm{C}$ for $24 \mathrm{hr}$.

(f) After termination of the incubation, the total radioactivity of each tube was counted, and then centrifugation was performed at $3,000 \mathrm{rpm}$ for $20 \mathrm{~min}$ at $4{ }^{\circ} \mathrm{C}$; the supernatant was decanted. and the radioactivity of the precipetate was counted with the Aloka NDW 35 ID type Scintillation Counter.

The standard was prepared in each experiment and the sample was made duplicate.

(3) Determination of HCG

It was determined by HAIR because of its being present at high concentration. The UCG Titration Set of Denber Chemical Corp. (being sold by Kyorin Yakuhin K.K. in Japan) was used.

Before starting the assay, an operation using acetone was performed for the purpose of extracting HCG in the blood; centrifugation was repeated till the supernatant becomes totally clear, and then this supernatant was made a sample. The lower limit of sensitivity of this method was almost $1 \mathrm{Iu} / \mathrm{m} l$.

\section{Results}

\section{1) A study on the incubation time}

For the determination of an appropriate incubation time, the placental tissue immediately after delivery at term was incubated for $1 \mathrm{hr}, 2 \mathrm{hr}$ and $4 \mathrm{hr}$, and the HPL content in the medium then used was measured by immuno-assay. The concentration of HPL in the incubated medium showed the highest value $(68.4 \pm 4.78)$ in $2 \mathrm{hr}$ incubation declining in $1 \mathrm{hr}(51.6 \pm 4.53)$ and $4 \mathrm{hr}(56.8 \pm$ 4.90). However, these values were all higher than those obtained by homogenization $(44.0 \pm 3.27)$. (unit: $\mu \mathrm{g} / \mathrm{m} l)$.

Therefore, the short-term incubation system based on the 2-hr incubation was employed in all experiments to follow.

\section{2) Prolactin activity in the chorionic tissue}

As indicated in Figure 1, prolactin was so little that determination of it was impossible from the early stage to the 17 th week of pregnancy, but it became possible to determine for the first time in the 19th week, and thereafter it increased sharply to show the highest value of $373,20 \pm 241.72 \mathrm{U} / \mathrm{g}$ (NHI- 


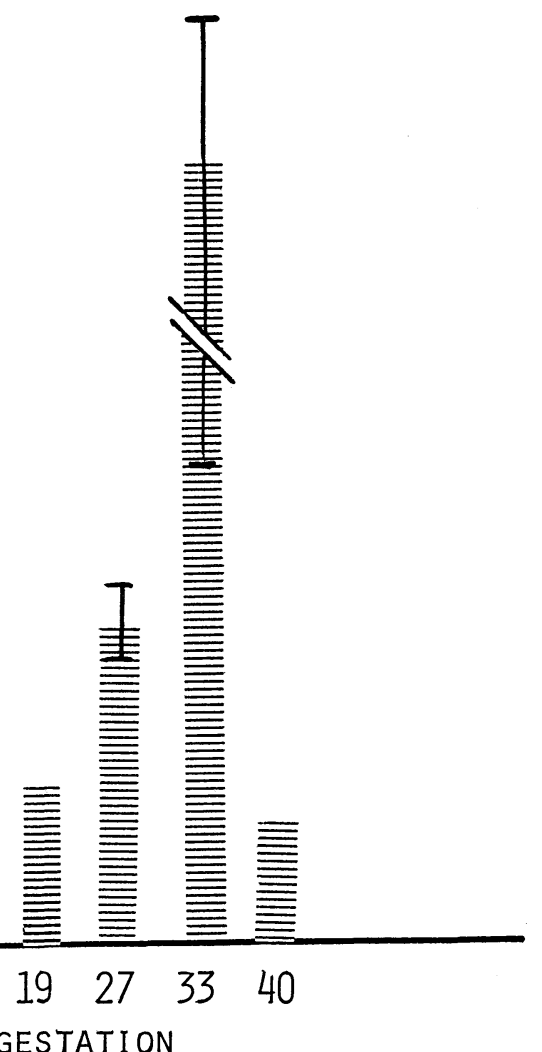

Fig. 1. Prolactin activity in incubated medium of trophoblast (Bioassay).

Prolactin- $\mathrm{B}_{2}$ ) in the $33 \mathrm{rd}$ week.

It stood at $44.71 \pm 0.88 \mathrm{MU} / \mathrm{g}$ in the 40 th week.

Meanwhile, the prolactin activity in the molar tissue could not be determined by this bioassay.

3) HPL content in the placental tissue extract in various weeks of pregnancy

As regards the HPL concentration released in the medium in the incubation experiment, the HPL concentration per $1 \mathrm{~g}$ in the placental tissue and chorionic tissue rose with gestational months; and in the 10th month of pregnancy, it reached $69 \mu \mathrm{g} / \mathrm{g}$, some ten times that of the early stage as shown in Figure 2.

\section{4) HPL content in the molar tissue}

When the HPL concentration in the incuba- tion medium was determined by the same method, it tended to be high in the 3rd month of pregnancy of hydatidiform mole as compared with that in the 3rd month of normal pregnancy as shown in Figure 3. However, no difference was observed between the two in the 4 th month of pregnancy.
5) HPL concentration in the monolayer cell culture medium
The monolayer cell culture was performed on each case of the molar chorionic villi and normal pregnancy collected at the artificial abortion in the 3rd month of pregnancy, and the concentration of HPL released in the medium was measured by RIA, the results of which were shown in Figure 4.
In the normal chorionic villi, the con- centration increased daily; however, in the 


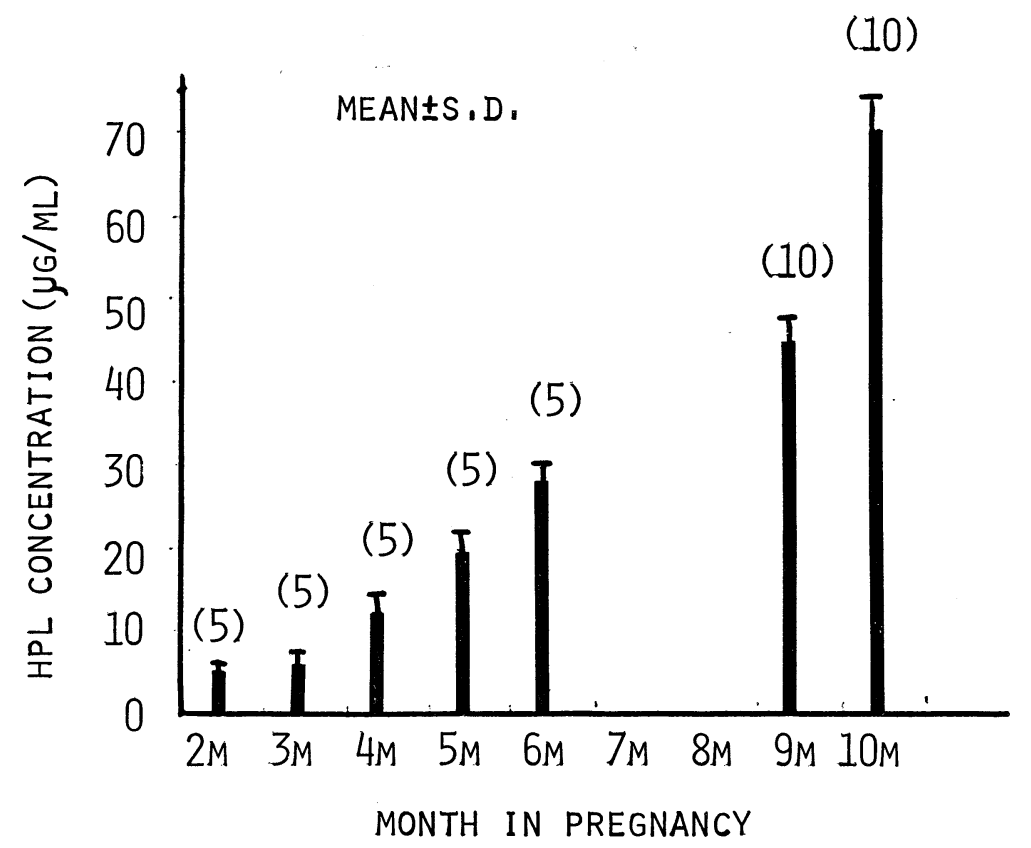

Fig. 2. HPL contents in the incubated medium of placental tisse in various months gestation. The number of samples are in parentheses.

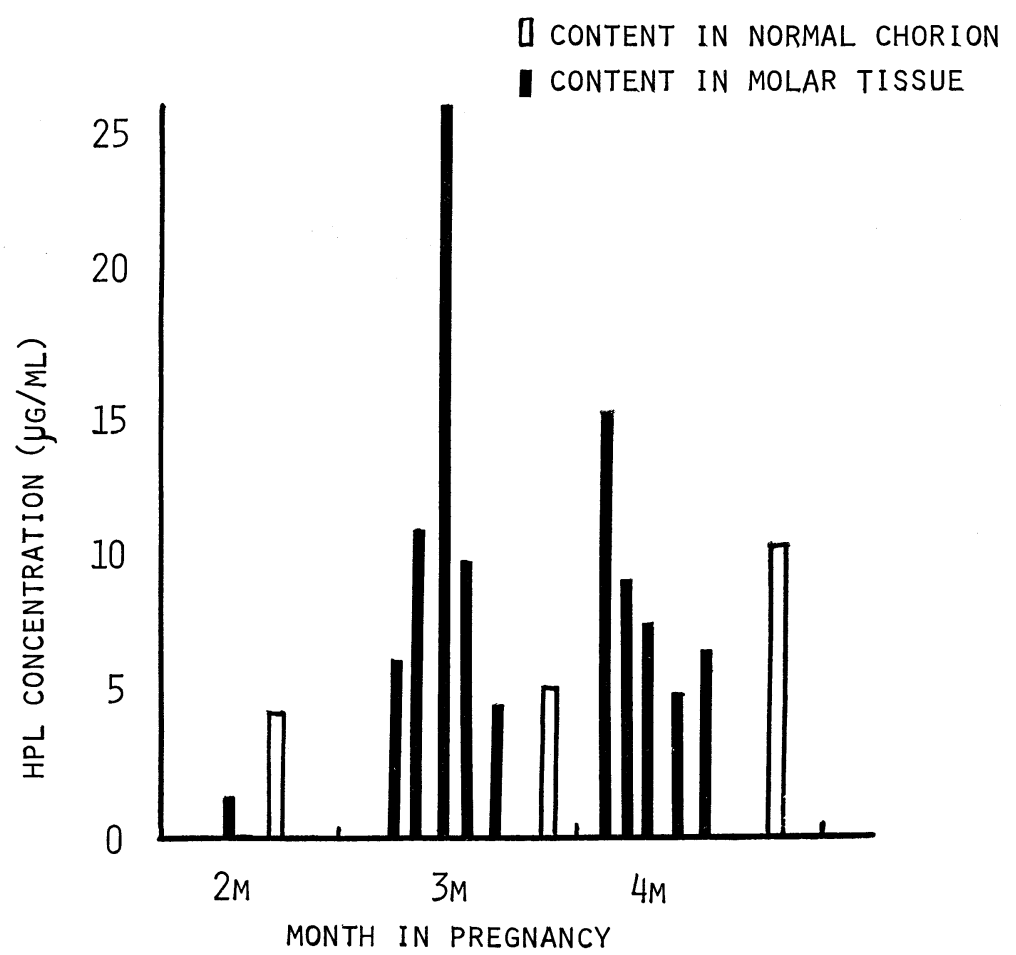

Fig. 3. HPL contents in the incubated medium of molar tissue (HAIR). 


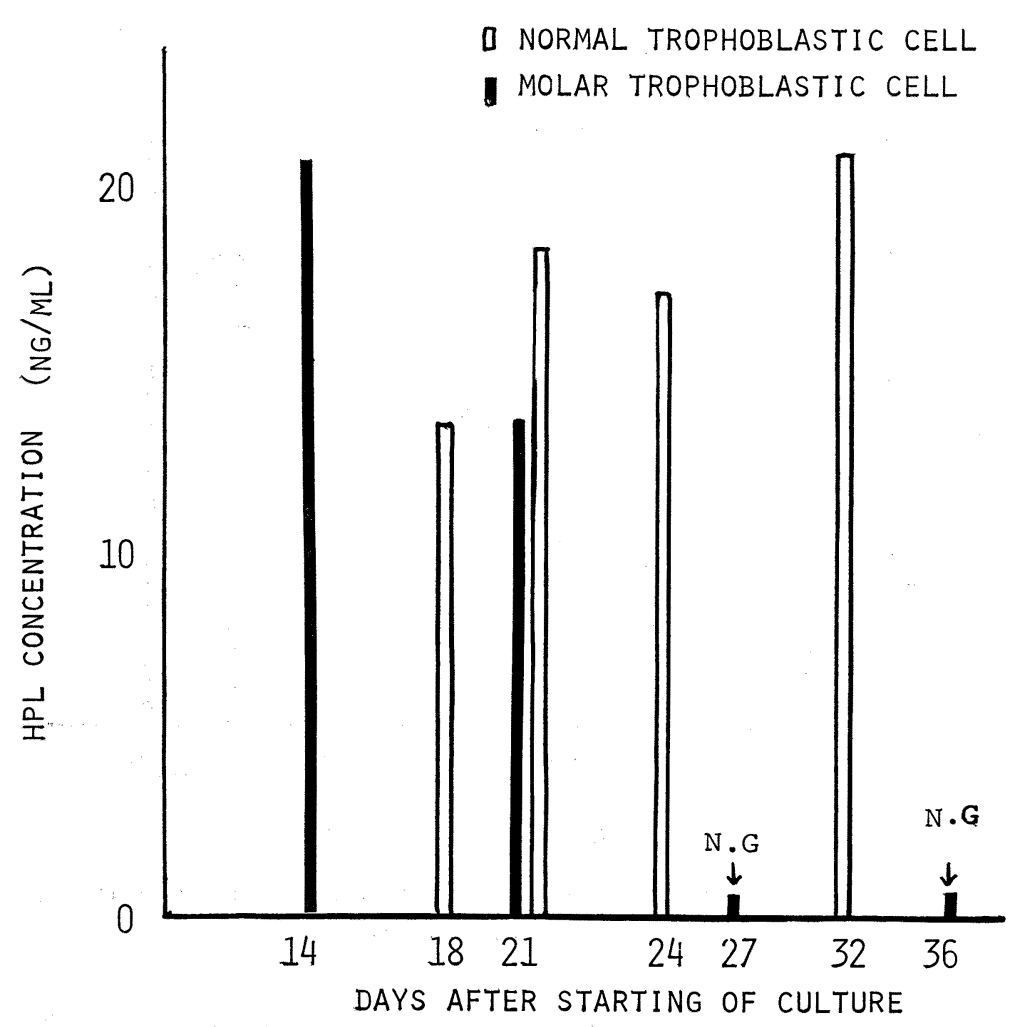

Fig. 4. HPL contents in cell culture medium. N. G means negative for assay.

case of molar chorionic villi, a considerable HPL production was observed in 2 weeks, but thereafter the HPL production decreased gradually and it was hardly noted on the 27 th day onward after starting of the culture.

6) Relation between the HPL concentration in maternal serum at term before the onset of the labor on the one hand and the weight of baby and the weight of placenta at birth on the other

The HPL concentration in the maternal serum at term of pregnancy and the weight of neonates at birth showed a significant correlation, albeit with a low correlation coefficient $\mathrm{r}=0.56(\mathrm{P}<0.05)$ (Fig. 5).

On the other hand, a look at the correlation between the HPL concentration and the weight of the placenta at birth showed that no correlation was observed with the correlation coefficient of $r=0.03$ (Fig. 6).

\section{7) Determination of HPL by RIA}

A micro-determination of the HPL concentration was made by the RIA system. A typical standard curve as shown in Figure 7 was obtained. $10 \mathrm{ng} / \mathrm{m} l$ to $100 \mathrm{ng} / \mathrm{m} l$ was used as the limit of determination following fundamental experiment of sensitivity, precision, accuracy and specificity.

\section{8) Comparison of HAIR and RIA}

A simultaneous determination by the RIA and HAIR was made on the serum in 18 identical cases, and comparison was made of them.

As a result, a high correlation was observed between the two, with the correlation coefficient expressed in $\mathrm{r}=0.86$ and the regression line in $\mathrm{Y}=1.22 \mathrm{x}+1.49$ (Fig. 8). 


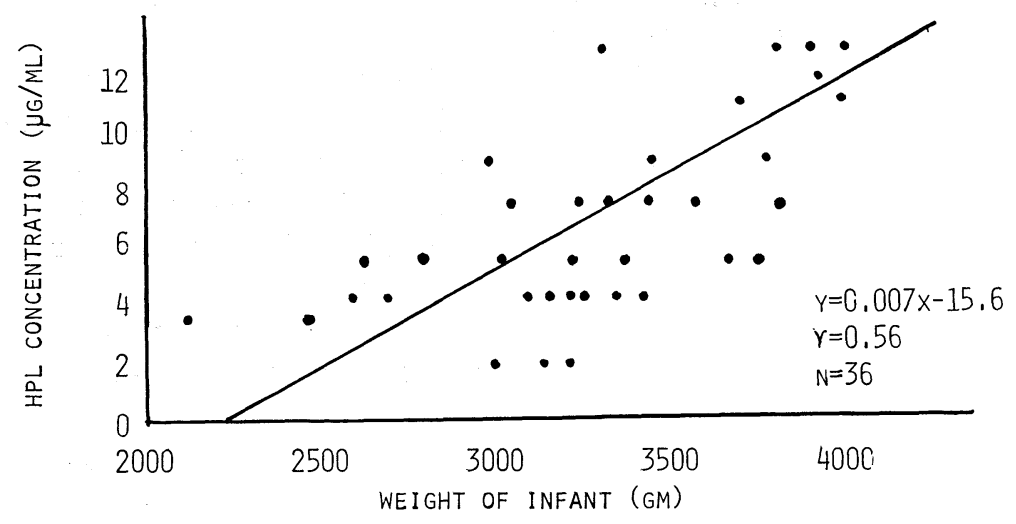

Fig. 5. Relationship between maternal HPL and infant weight at term (HAIR).

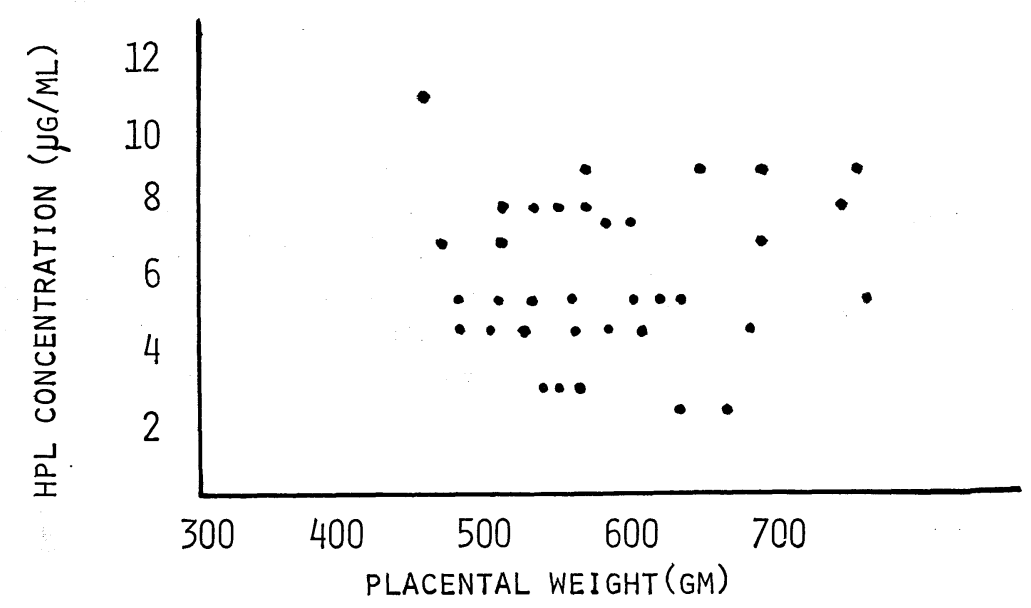

Fig. 6. Relationship between maternal HPL and placental weight at term (HAIR). No correlation is obserbed.

9) Serum HPL concentration in normal pregnancy and in trophoblastic disease

The HPL level in the serum was determined by RIA on 97 cases of normal pregnancy.

HPL was observed in the blood from the 7 th week of pregnancy; thereafter, it rose sharply and reached a plateau with ca. $9.5 \mathrm{ng} / \mathrm{m} l$ in the 9th month of pregnancy (Fig. 9).

Further, the HPL concentration was measured in a total of 26 cases of trophoblastic disease (hydatidiform mole 20 cases, destructive hydatidiform mole 3 cases and chorionepithelioma 3 cases).
The results being as shown in Figure 9, HPL was detected in many cases even in trophoblastic disease. However, even in that case, the highest value stood at $180 \mathrm{ng} / \mathrm{ml}$, and it could not be detected in some cases.

As regards the postoperative isolated preparation, a histrogical examination was made on it to confirm its diagnosis.

10) Serum HCG concentration in normal pregnancy and trophoblastic disease

Serum HCG was assayed on the serum of 97 cases af normal pregnancy and that of 


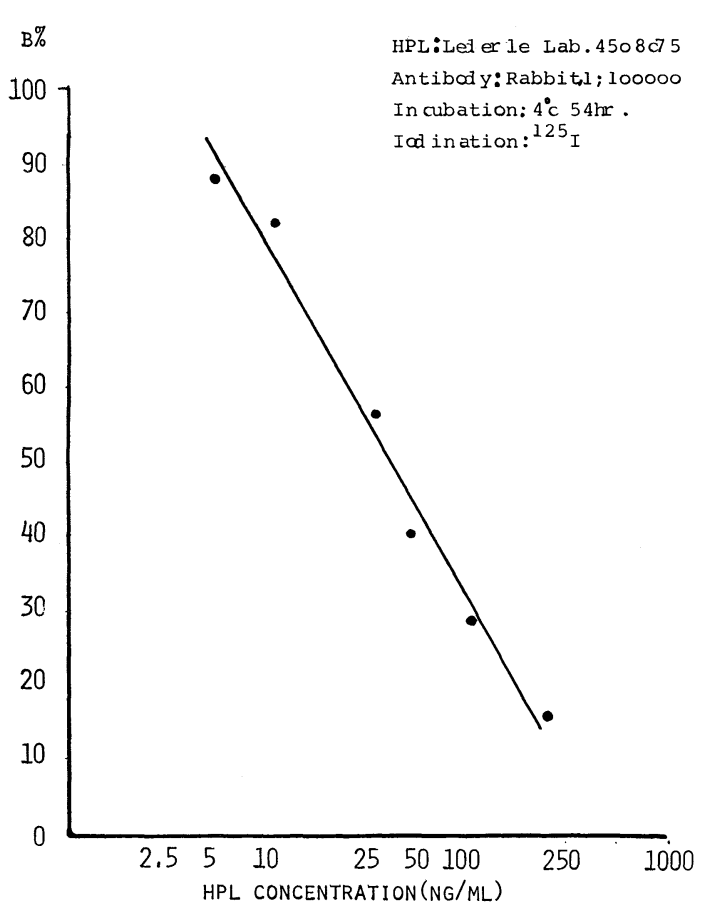

Fig. 7. A typical standerd curve of ${ }^{125} \mathrm{I}$ HPL for RIA. The limit of sensitivity is $10 \mathrm{ng} / \mathrm{ml}$ to 100 $\mathrm{ng} / \mathrm{ml}$.
26 cases of trophoblastic disease mentioned above.

The results being as shown in Figure 9, the HCG concentration in normal pregnancy showed a peak, reaching ca. $150 \mathrm{IU} / \mathrm{m} l$ in the 3rd month of pregnancy; thereafter, it fell off gradually and maintained a mainly same concentration.

The HCG concentration in the serum of molar patients was higher than that of the normal pregnants in many instances; however, some showed a level as high or slightly lower than that of the normal.

The HCG concentration was observed in sera from destructive mole and chorionepithelioma; however, any conclusion as to HCG concentration could not be drawn because of paucity of samples.

\section{1) HPL/HCG ratio in serum from normal} pregnancy and trophoblastic disease

The blood HPL/HCG ratio in each case was calculated on the serum of normal pregnancy 97 cases and trophoblastic disease 26 of which determination was made above.

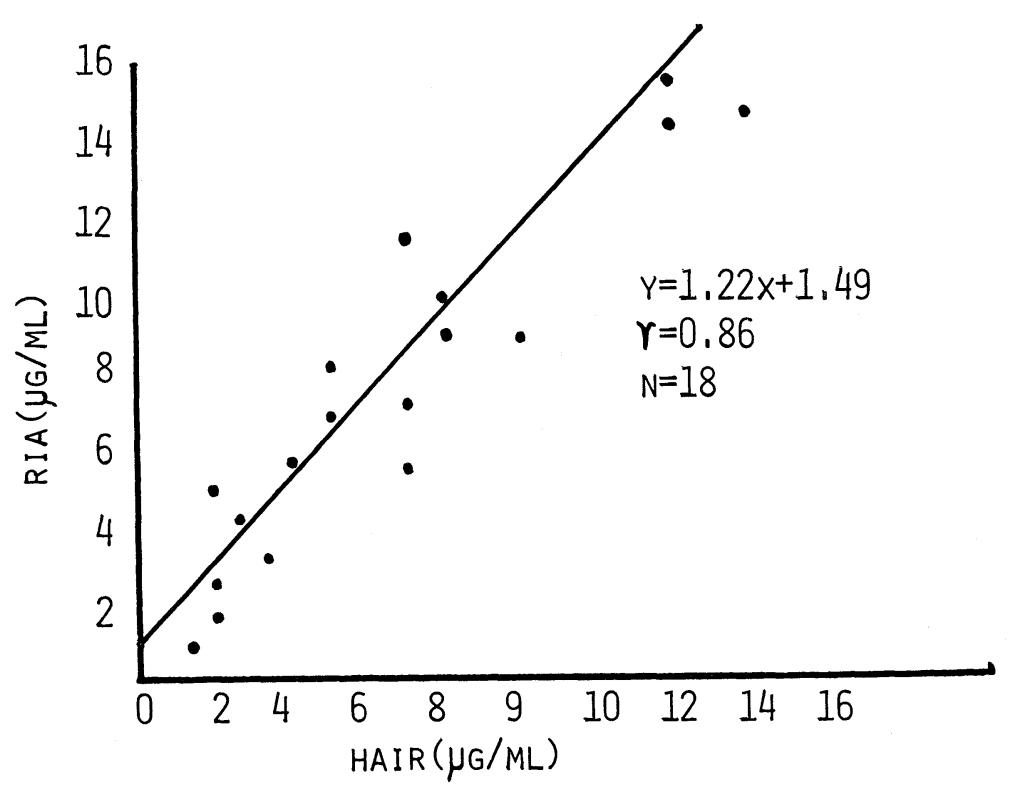

Fig. 8. Comparison of RIA with HAIR for HPL. High correlation is seen. 


\section{SERUM HCG}

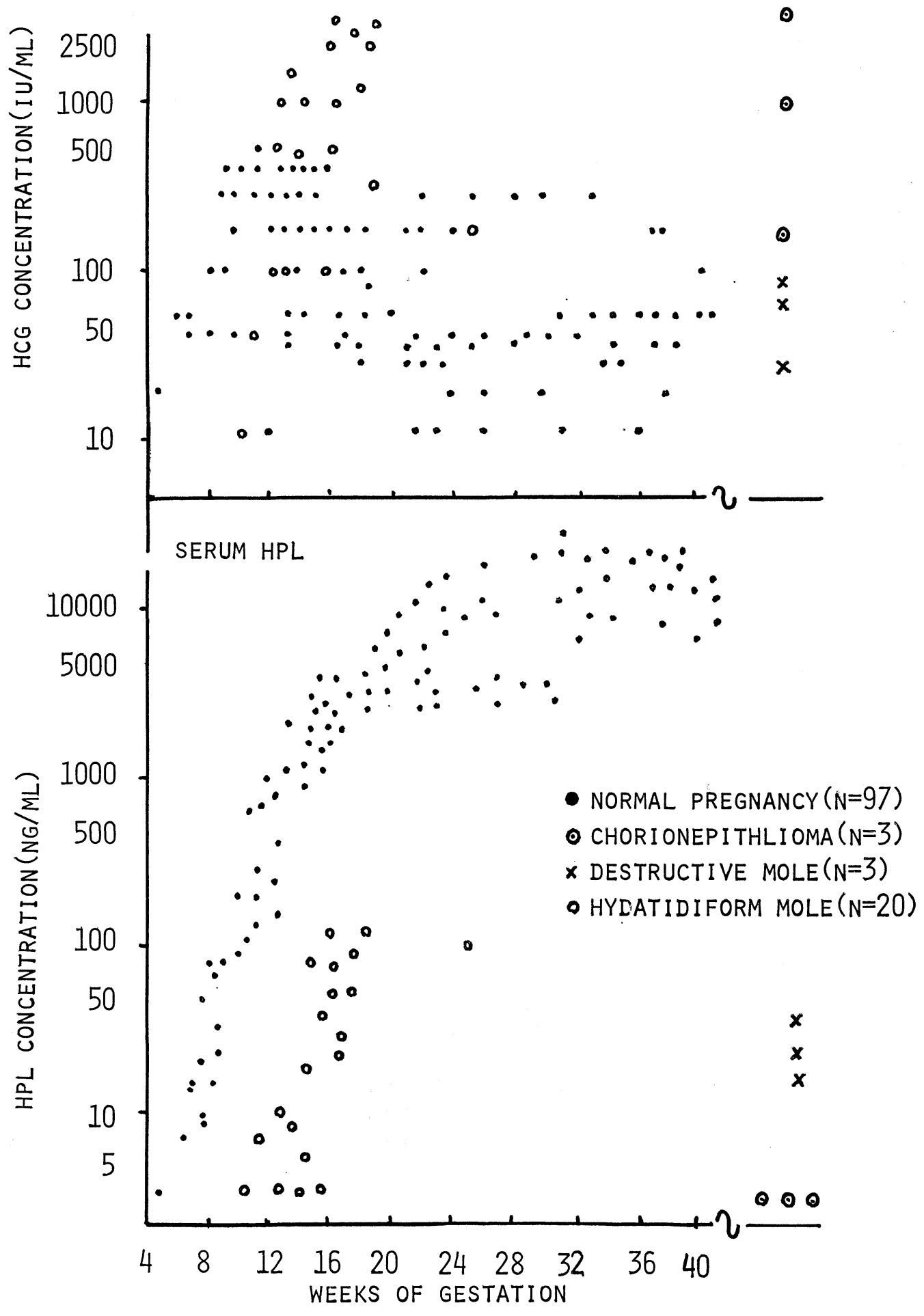

Fig. 9. Serum HCG and HPL levels in normal pregnancy and in patient with trophoblastic disease. 


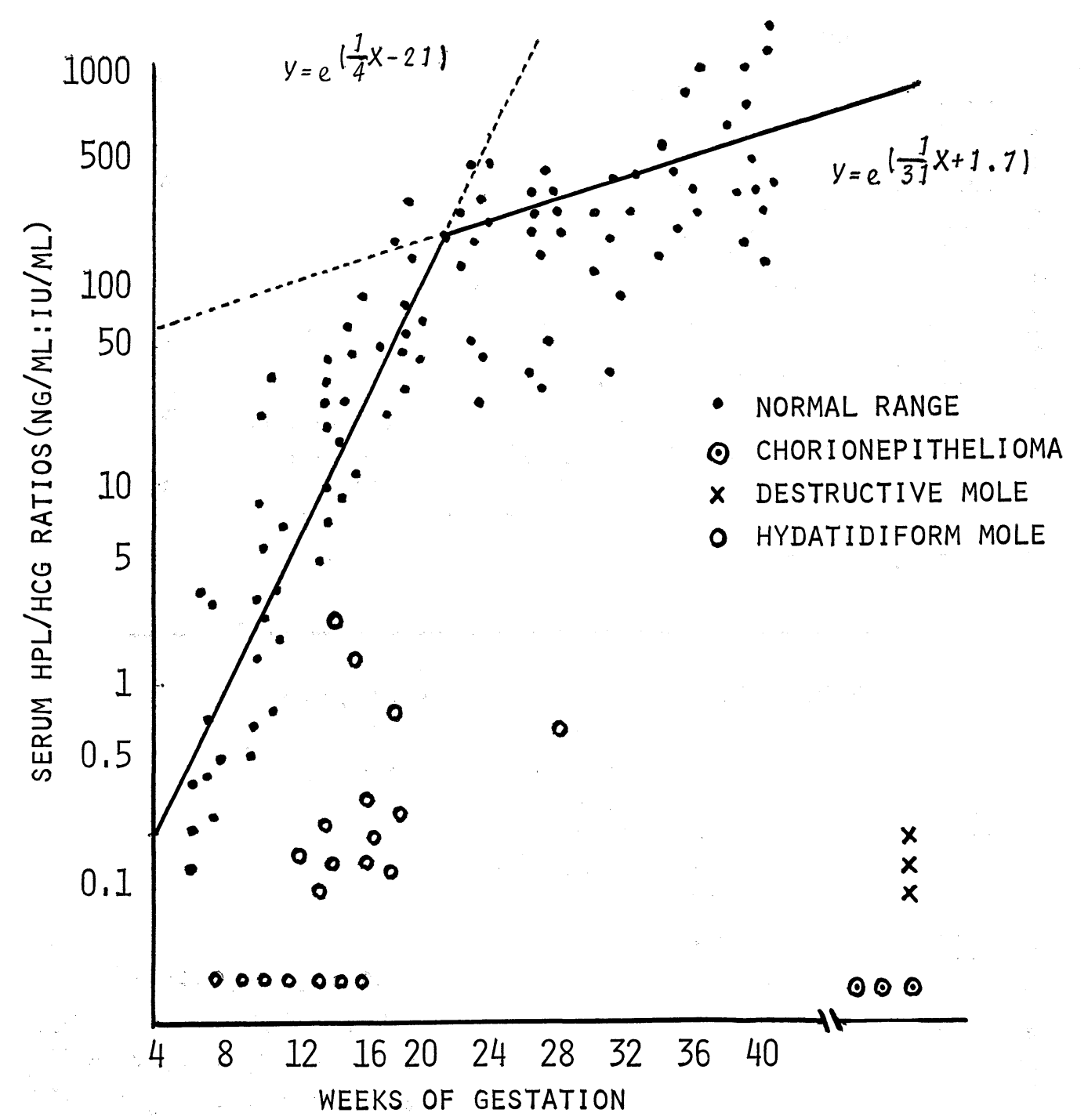

Fig. 10. Ratio of serum HCG to HPL in normal pregnancy. Good correlation is seen between this ratio and gestational months. Low values are showed in trophoblastic disease.

As shown in Figure 10, the HPL/HCG ratio in normal pregnancy increased with the advance of pregnant months and showed a close correlation $(\mathrm{r}=0.83, \mathrm{P}<0.01)$.

In trophoblastic disease, meanwhile, the ratio was obviously lower than the normal with the advance of gestational months.

12) Time for clearance of HPL (half life) from the blood

The blood was collected at time intervals, namely before delivery of a fetus or hydatidiform mole and at $10 \mathrm{~min}, 30 \mathrm{~min}, 60 \mathrm{~min}$ and $24 \mathrm{hr}$ after delivery.

The blood HPL decreased rapidly both in the serum of normal pregnancy and of hydatidiform mole.

As for the physiological half life, it was 


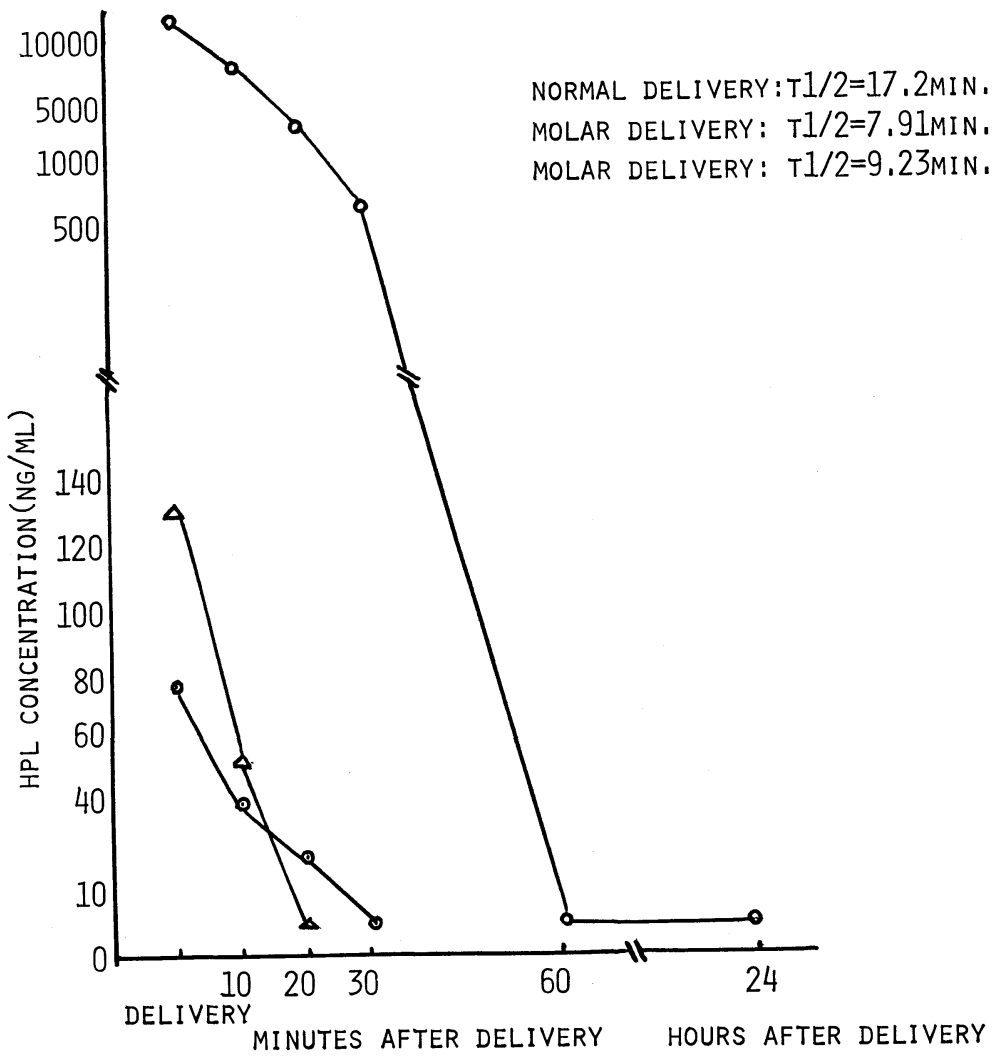

Fig. 11. Disappearance rate of HPL from the sera of a normal subject after delivery and molar subjects after $\mathrm{D} \& \mathrm{C}$.

calculated according to the method of Gitlin et al. (1960). That is,

$$
\begin{aligned}
\mathrm{T} 1 / 2 & =\frac{0.693}{\mathrm{r}} \\
\mathrm{r} & =\frac{\log \mathrm{Xs}_{1}-\log \mathrm{Xs}_{2}}{0.434 \mathrm{x} \Delta \mathrm{t}}
\end{aligned}
$$

here

$\mathrm{Xs}_{1}, \mathrm{Xs}_{2}$ : Blood HPL level in $\mathrm{S}_{1}, \mathrm{~S}_{2}$ time.

$\Delta \mathrm{t}$ : Time interval of $\mathrm{S}_{1}, \mathrm{~S}_{2}$ (min)

As a result, the half-life was calculated as $17 \mathrm{~min} 21 \mathrm{sec}$ in a normal pregnancy and 7 min 91 seconds and 9 min $23 \mathrm{sec}$ respectively in 2 cases of hydatidiform mole (Fig. 11).

\section{Discussion}

(1) The role of HPL in pregnancy

It has been known that the placenta seems to possess a hormone-producing activity independent of the pituitary. It is clear that pituitary hormones are essential for ovulation and implantation and placental hormones are also necessary for the maintenance of gestation. Since the finding of a prolactin like placental hormone, studies on it have made a rapid progress.

It has also been known that this hormone is very akin to the growth hormone $(\mathrm{HGH})$ in the aminoacid structure and molecular weight. And its structural formula seems to be decided shortly (Li./1971/).

With the great advances in the extracting and refining processes of this protein, research into more basic aspects of biological role of HPL is begining to reveal and many reports on it have been published. 
Firstly, as the sommatotropic action, mention can be made of the positive tibia test in hypophysectomized animals (Josimovich \& MacLaren 1962; Kaplan \& Grumbach 1964) and an increase in the uptake of ${ }^{35} \mathrm{~S}$ in the costal cartilage of rats (Kaplan \& Grumbach 1964; Franchimont 1965); further, Friesen et al. (1965) and Florini et al. (1966) administering HPL to the hypophysectomized animals said that an increase in the body weight paralleled to the doses was observed; while, Josimovich \& Mintz (1968) reported that the uptake of ${ }^{14} \mathrm{C}$-glycine in the muscle increased in the hypophysectomized animals in vivo, but such a phenomenon was not observed in vitro.

In any case, the HGH-like action itself seems to be considerably weak.

Secondly, it may also be true that HPL has a lactogenic or mammotropic action. Many investigators observed that placenta had the positive pigeon crop sac test (Ito \& Higashi 1961; Josimovich \& MacLaren 1962).

It was also tested by author, and I assumed that placental extract had surely biological activity smilar to prolactin (Fig. 1).

But this biological activity was not paralleled to its immunological activity. These findings have led to an idea that HPL was different from prolactin in biological activity.

It is also known that there is the potent luteotropic effects of HPL demonstrated by maintenance of decidual reaction in mice (Josimovich et al. 1963).

However, whether or not these findings are independent of HPL or depend on its concert action with other hormones, biological role of HPL still underfined.

Then, attention is drawn to the metabolic action of HPL.

As to this point, mention is made in reports of the FFA-mobilizing action (Riggi et al. 1966), the anti-insulin action and the insulinsecretion-increasing action (Samaan et al. 1966; Grumbach et al. 1968), a slight P, K, Na-accumulating action and $\mathrm{Ca}$ excreting action (Samman et al. 1966), and, Mochizuki et al. (1971) administering HPL to pregnant rats observed a significant increase in the body weight.

Whereas Spellacy (1966) denied the correlation between the weight of a fetus and the maternal blood HPL level at term, Saxena et al. (1968) showed the correlation between the two.

In the author's experiment, a significant correlation was observed between the two, low as it was, and therefore, HPL seems to activate directly the metabolism of the pregnant woman and thereby many affect indirectly in the growth of the fetus.

That is, as stated by Grumbach (1971), the existence of HPL at high concentration in the maternal serum would mean that HPL has an action to lower the utilization of glucose by mobilizing fats of the mother body and to supply glucose, amino acids and minerals to the fetus by accumulating $\mathrm{Na}$ and $\mathrm{K}$.

As reported by Spellacy et al. (1966) and Sciarra et al ((968), there was observed no correlation between the HPL level and the weight of the placenta (Fig. 6).

This might show a possibility that the HPLproducing cells will not exist uniformly over the chorionic villi, as compared with a report rendered by Saxena et al. (1968), namely, the HPL activity was not observed despite the chorionic tissue being observed clearly in the cases of recurrence of trophoblastic disease.

\section{(2) Determination of HPL}

Since HPL has the prolactin action and the $\mathrm{HGH}$ action in combination, I once attempted to determine HPL by the pigeon crop sac assay, but was unable to overcome the low sensitivity of these Bioassays (Fig. 1).

In this study, the immuno-assay is being employed mainly.

I carried out determination by using RIA and HAIR.

As regards HAIR which has been established as a clinical examination method by Wide et al. (1962) on HCG, I carried out the HPL coating to sheep's RBC using BDB about which Odajima (1972), and Theppisai (1971) 
et al. have already reported.

This method has such merits which the RBC was stable, the end point was clear, reactive time was short and chemical lingage was strong compared to tannic acid coupling technique.

As for RIA, various methods for separating the Bound (B) from the Free (F) have been devised since this system was published by Glick (1963) and Greenwood et al. (1963).

In separating the B from the F, I employed the double antibody method which is considered to have higher accuracy; however, as a routine method for determination, it still leaves something to be desired, when account is taken of the incubation time, presence of a none specific inhibitor, high cost and inconvenience in use.

Then, comparison was made between RIA and HAIR in same samples, a highly significant correlation of $\mathrm{r}=0.86(\mathrm{P}<0.01)$ was observed between the two (Fig. 8).

Theppisai et al. (1971); Mochizuki (1972) et al. also made a comparative study of RIA and immuno-assay and observed a high correlation between the two; however, it seems to be reasonable to use RIA and HAIR each in its proper way according to the objects of determination.

(3) HPL concentration in the maternal serum and chorionic tissue

Reports on the HPL production in the chorionic tissue are still little as compared with those on HCG.

Using the immuno-fluorescent antibody method, Sciarra et al. (1963) and Saxena (1968) et al. proved that HPL was present in syncytiotrophoblast of the chorionic villi; further, Josimovich \& Astwood (1964) showed that HPL was extracted from the placenta but could not be detected from the fetus or pregnant putuitary. So it is recognized widely that HPL is secreted and released from the placenta.

As to the level of HPL in the maternal serum during pregnancy, Beck et al. (1965) and
Spellacy et al. (1966) using RIA rendered reports on it.

According to their reports, HPL presented itself in the blood in the 5th-8th week of pregnancy and thereafter rose with the gestational months reaching a plateau at term.

In the results obtained by the author too, the HPL concentration was observed from the 7 th week of pregnancy and reached a plateau, showing the concentration of ca. $9.5 \mu \mathrm{g} / \mathrm{m} l$ in the $36 \mathrm{th}$ week of pregnancy.

The HPL concentration at term varies greatly with researchers and method for assay.

This discrepancy considered to be attributable to that a uniform standard HPL is not available.

When one lookd at the relation between gestational months on the one hand and the weight of a fetus and weight of the placenta on the other, one can surely presume that the rise in the maternal HPL corresponds to the curves for an increase in the weight of the fetus and placenta.

Then, a lood at the relation between the HPL level in the maternal serum before the onset of labor and the HPL content per $1 \mathrm{~g}$ of the placenta shows a significant correlation ( $\mathrm{r}=0.62 \mathrm{P}<0.05)$, low as it is, which leads to a suggestion that there is a relation between the growth of the placenta and the rise in the HPL level.

Moreover, the HPL-content of the chorionic villi and the HPL level in maternal serum showed an almost similar increase in gestational months.

Viewed from these facts coupled with the results of experiments, it can be seen that the HPL-level is proportional to the growth of fetuses.

However, the fact that the HPL level in the maternal serum is not correlated with the weight of the placenta is probably because various factors, in addition to HPL, take part in the growth of fetuses in a complex manner.

HPL is observed also in the serum of patients with trophoblastic disease (Grumbach \& Kaplan 1964; Saxena 1968; Samaan et al, 
1966: Grumbach et al. 1968).

According to the fact that HPL is synthesised by the chorionic villi, the finding would be probable.

However, there is hardly any report on the way HPL is produced in the tissue of hydatidiform mole; only Josimovich \& Astwood (1965) reported that the HPL activity in 1 case of the molar tissue was about 3 times as high as that of the normal, and this is the only report available.

As such, I examined the HPL concentration in the molar tissue on 10 cases of the 2nd-4th month of pregnancy using the incubation system as with the normal chorionic villi (Fig. 3).

As a result, it was surmised that there might be considerable HPL production in the molar tissue.

It is difficult to provide an accurate answer to the result; however, the mechanism of production and release of HPL in the molar tissue seems to be somewhat different from that of the normal chorionic villi.

A fundamental study on this point including HCG seems necessary.

Further, I effected the monolayer cell culture, though only on two cases, namely the normal chorionic villi in the 2 nd month and that of hydatidiform mole in the $3 \mathrm{rd}$ month to find that an almost constant HPL production from the chorionic cells of hydatidiform mole seems to be the same as that of the normal first, but ceases to be seen after full 3 weeks. Such findings suggest that there is some difference on mechanism between the two (Fig. 4).

(4) On diagnosis of trophoblastic disease by HPL/HCG ratio in the blood

The principle of early diagnosis and treatment remains the same even in the case of trophoblastic disease and there is no doubt that the differential diagnosis of mole in utero is important.

The urine HCG has been mainly used as an index up to date; however, as shown in Figure
9, it is risky to use HCG alone in diagnosis.

In other words, the early diagnosis of it becomes difficult, if the HCG level is within the normal range.

According to Saxena (1968) who reported that the HPL was observed in the serum of molar patients, the HPL level in the serum of patients with hydatidiform mole was lower than that in the early stage of normal pregnancy; and a dissociation phenomenon with HCG was seen.

Results as shown in Figures 9 were obtained by the measurement of HCG and HPL levels in identical serum of normal pregnancy 97 cases and patients with trophoblastic disease 26 cases; further, when the HPL/HCG ratio was calculated on these cases, this ratio rose with the gestational months in normal pregnancy, but it fell off clearly in trophoblastic disease; therefore, it is considered that the HPL/HCG ratio can serve as a useful index in the diagnosis of trophoblastic disease, normal pregnancy after hydatidiform mole and repeated hydatidiform mole.

Goldstein et al. (1971) reported that in the serum of trophoblastic disease of which degree of malignancy is considered to be advanced histologically, the HPL activity fell off in proportion to the degree of malignancy.

That is, they said that the HPL could indicate the degree on malignancy in trophoblastic disease.

In the results of the anthor, however, there were some cases where HPL was negative even in the serum of patients with hydatidiform mole, and a follow-up of about 1 year showed that these cases did not become aggravated. In this aspect, much remaines to be clarified in the future.

The question arises regarding the fact that the possibility of the HPL/HCG ratio showing low values in the early stage of pregnancy, early abortion or intra-uterine fetal death cannot be ruled out.

As regards this question, ultrasonography, determination of $\alpha$-fetoprotein (Sato \& Takeuchi, 1973) and so forth seem necessary. 
The half time of HPL is said to be 20 min or 30 min (Kaplan et al. 1965; Beck \& Daughaday 1967).

According to the results of the author, when the HPL level after normal delivery was followed up, detection of it became impossible $60 \mathrm{~min}$ later, and its physiological half time was $17 \mathrm{~min}$ and $21 \mathrm{sec}$ (Fig. 11).

That of molar patients was shorter, standing at $7 \mathrm{~min} 91 \mathrm{sec}$ and $9 \mathrm{~min} 23 \mathrm{sec}$ respectively on 2 cases, which is about one half of the normal; this is probably because there is some difference on HPL between the normal case and hydatidiform mole.

In any case, this rapid turnover rate is considered to be useful as a sensitive indicator of the endocrine function of the placenta.

However, whether or not it can be used as a means of assessing prognostic value of hydatidiform mole remaines still obscure.

\section{Acknowledgments}

The author is indebted to prof. Dr. Shoshichi Takeuchi and assistant prof. Dr. Masahiko Hiroi of Niigata University School of medicine, for their valuable advices and criticisms.

In this connection, I also wish to render thanks to Dr. Eiichi Odajima of this department for his technical advices.

\section{References}

Beck, P. L., M. L. Paker and W. H. Daughaday (1966). J. Clin. Endocr. 25, 1457.

Beck, P., W. H. Daughaday (1967). J. Clin. Invest. 46, 103.

Currie, A. R., J. S. Beck., S. T. Ellis and C. H, Read (1966). J. Pathol. Bacteriol. 92, 395. Dulbecco, R. and M. Vogt (1954). J. Exper. Med. 99, 167.

Elorini, J. R., G. Tonelli., C. B. Brever., C. Coppola., I. Ringler and P. H. Bell (1966). Endocrinology 79, 692.

Franchimont, P. (1965). Ann. Endocr. (Paris). 26, 346.
Friesen, H. (1965). Endocrinology 79, 692. Gitlin, D. and C. A. Janeway (1960). Advances Biol. Med. Phys. 7, 246.

Glick, S. M., J. Roth., R. S. Yallow and S. A. Barson (1963). Nature (Lond). 119, 784.

Coldstein, D. P. and P. Donald (1971). Amer. J. Obst. Gynec. 110, 593.

Greenwood, F. C., W. N. Hunter and J. S. Glover (1963). Biochem. J. 89, 144.

Grumbach, M. M., S. L. Kaplan., C. L. Abraham., J. J. Bell and F. A. Conte (1966). J. Clin. Endocr. 26, 478.

Grumbach, M. M. (1971). Second. Inter. Symp. on GH(Abstract) No. 16, 76.

Ito, Y. and K. Higashi (1961). Endocr. Jap. 8, 279.

Josimovich, J. B. and J. A. MacLaren (1962). Endocrinology 71, 209.

Josimovich, J. B., B. L. Astwook and D. A. Goss (1963). Ibid. 73, 410.

Josimovich, J. B. and B. L. Astwood (1964). Amer. J. Obest. Gynec. 88, 867.

Josimovich, J. B. and D. H. Mintz (1968). Ann. N. Y. Acad. Sci. 148, 488.

Kaplan, S. L. and M. M. Grumbach (1964). J. Clin. Endocr. 24, 80.

Li, C. A. (1971). Growth and Growthhormone. 17. Excerpta medica. Amsterdam.

Midgley, A. R. and G. B. Pierce (1962). $J$. Exp. Med. 115, 289.

Mochizuki, M., H. Morikawa., M. Mizutani., T. Cho and S. Tojo (1971) Journal of the Japanese Obistrical and Gynecological Society 23, 585 (In Japanese).

Morikawa, H., M. Mochizuki and S. Tojo (1971). Endocr. Japan. 18, 414.

Nicoll, C. S. (1967). Endocrinology 80, 641.

Odajima, A. and S. Takeuchi (1972). $O b$ stetrics \& Gynecology. 39, 203 (In Japanese).

Riggi, S. T., C. R. Boshart., P. H. Bell and J. Ringler (1966). Endocrinology 79, 692.

Samaan, N. S., C. C. Yen and D. Gonzales (1966). Program. 48th.

Annual Meeting of the endocrine Society, Cicago.

Sato, Y. and S. Tadeuchi (1972). The World of Obstetrics and Gynecology. 24, 535 (In 
Japanese).

Sato, Y. and S. Takeuchi (1973). Acta Obstetrica et Gynecologyca Japonica (In press).

Saxena, B. N. (1968). Amer. J. Obest. Gynec. 102, 115.

Saxena, B. N., S. L. Kaplan and M. M. Grumbach (1963). Nature (Lond). 199, 1005.

Sciarra, J. J. (1968). Amer. J. Obest. Gynec. 101, 413.

Spellacy, W. N. (1965). Amer. J. Obest. Gynec.
95, 115.

Spellacy, W. N., K. L. Carlson and S. A. Birk (1966). Amer. J. Obest. Gynec. 96, 115.

Spellacy, W. N., K. L. Carlson and S. A. Birk (1966). Amer. J. Obest. Gynec. 96, 1164.

Takahashi, T. (1970). Journal of the Japanese Obstetrics and Gynecology. 22, 379 (In Japanese).

Theppisai, H., D. R. Mishell. Jr. and R. H. Nakamura (1971). J. Clin. Endocr. 32, 382. 